\title{
The Flexible Bus Systems Using Zigbee as a Communication Medium
}

\author{
doi:10.3991/ijoe.v7i3.1579 \\ Razi Iqbal, Kenichi Yukimatsu, Tatsuya Ichikawa \\ Akita University, Akita, Japan
}

\begin{abstract}
This paper describes a research on The Flexible Bus Systems (FBS) using Zigbee as a communication medium. The Flexible Bus System is a demand responsive transit (DRT) which is more efficient and convenient in a sense that it entertains passenger's demands and gives bus locations in real time. The real time synchronization of The Flexible Bus System makes it information rich and unique as compared to other DRTs. The Flexible Bus Systems is a system that can replace the Traditional Bus Systems with its flexibility and efficiency. This paper discusses the use of wireless technologies in The Flexible Bus Systems and how to make it more reliable using short range wireless technology Zigbee.
\end{abstract}

Index Terms-ITS, Zigbee, Mobile communication, DRT, RFID

\section{INTRODUCTION}

The main objective of this paper is to do a research on the use of short range wireless technology called "Zigbee" in Demand Responsive Transit (DRT), making it much more efficient, reliable and less expensive. This research is not the only way to develop this kind of a system and by no means suggested the best solution but it can definitely be one of the better alternatives we have till date and can be used in the areas where there are no 3G, WiMax or other long range wireless technologies available. This research will also help us understand the potential of Zigbee. Till now Zigbee is being used as in-house or in-vehicle technology but this research brings an idea of using Zigbee as communication tool for Inter-Vehicle and Vehicle to Infrastructure. Using Zigbee to communicate between Bus and the Bus Stop will also reduce the total cost of the system as Zigbee devices are far cheaper than $\mathrm{WiFi}, 3 \mathrm{G}$ and WiMax devices. Due to the fact that Zigbee is low power as compared to other short range wireless technologies like $\mathrm{WiFi}$, this system can be deployed in mountainous areas where power is a major concern.

The algorithm of Flexible Bus System is devised in a way that this system replaces the scheduled bus lines systems and buses can dynamically change their routes according to passenger's demands. Passengers are informed about the real time location of the buses which makes it easy for the passengers to decide whether to ride a particular bus or not making this system passenger friendly.

\section{SYSTEM DESCRIPTION}

Most of the researches today on DRT are carried out in a way that communication medium is long range Wireless technologies like 3G (cellular data) as shown in the Fig. 1.

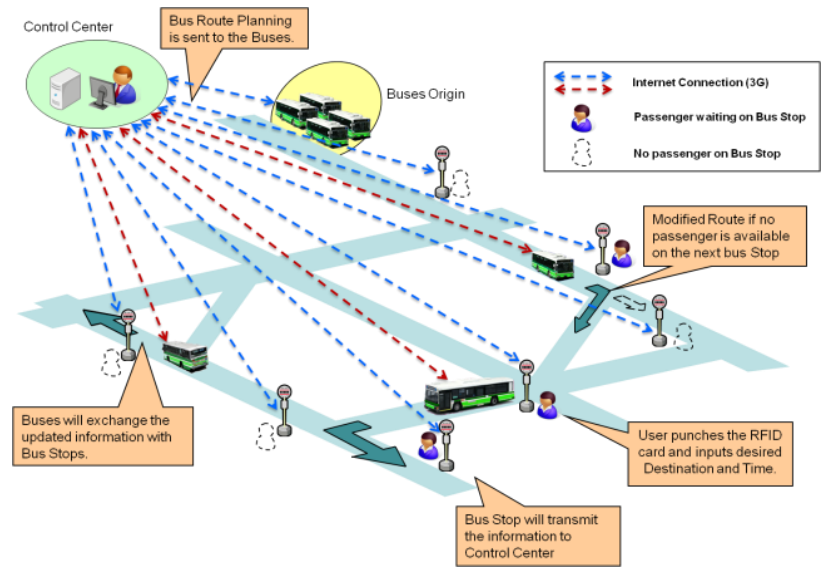

Figure 1. Example of typical DRT System Model

Everything in the System is connected to the Control Centre and all the information is shared with the Control Centre. Communication between Bus and Control Centre is through $3 \mathrm{G}$; similarly communication between Control Centre and Bus Stop is through 3G. Installing the 3G modules on Bus Stop and Bus which are more than 1 in most of the cases will greatly increase the total installation cost of the system. Following are some drawbacks to this approach.

1. Installation cost is very high.

2. Maintenance cost is very high.

3. High power consumption.

4. Cannot be applied in areas where there are no long range wireless (3G, WiMax) signals available (rural or mountainous areas).

5. Licensing can be an issue in some parts of the World.

To overcome these problems we propose a model which is less costly than the system discussed above. We call our proposed system "The Flexible Bus System". This paper will only include the wireless communication part of this system. Control Centre is connected to Bus Stops through internet (Wireless or Wired). Fig. 2 shows our proposed system. We are considering both Wired and Wireless internet because if this system is to be deployed in cities, wired internet facility is easily available but if this system is to be deployed in remote areas the wired internet facility is not easily available so we are considering Wireless internet in those cases. 


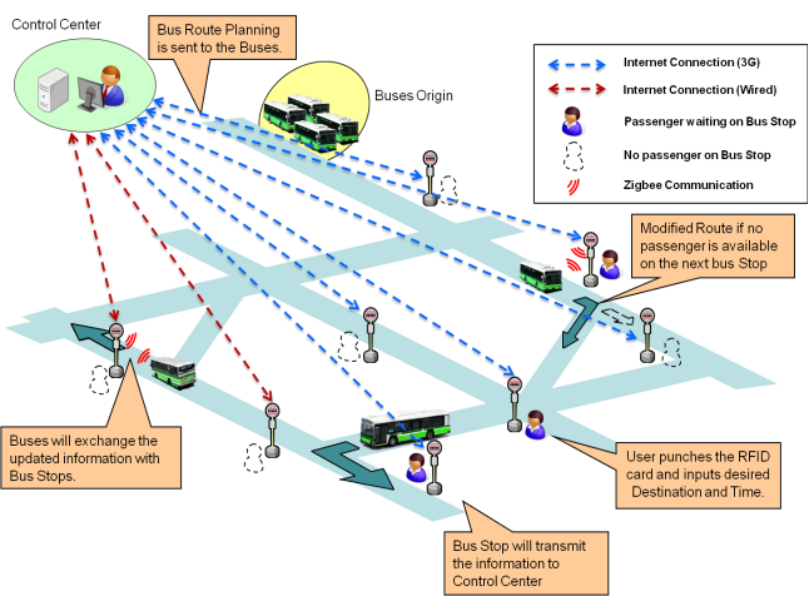

Figure 2. Proposed Flexible Bus Systems Model

Bus Stop and Bus are connected through short range Wireless Technology "Zigbee". An interesting feature here is that Bus and Control Centre are not connected to each other directly, they communicate to each other through Bus Stop, means the information from Control Centre is first transferred to Bus Stop and then from Bus Stop to Bus vice versa. This way there will be no need for $3 \mathrm{G}$ module installation in Buses. This will greatly reduce the total cost of the system.

The Bus Stops in this system are very smart and we call them "Intelligent Bus Stops". These Bus Stops are equipped with different devices like RFID card reader; Touch Screen etc. The passengers carry RFID card which contains all the information about the passenger. Whenever a passenger goes to the Bus Stop, he/she will punch his/her RFID card to those RFID card readers installed at Bus Stop and gets recognized by the system. After getting recognized by the system, the passenger can enter the destination and will get the response from the system e.g. on which Bus to ride and how much is the wait time, leaving the decision of riding the Bus to the passenger.

\section{PROPOSED ALGORITHM}

The algorithm for this system is devised in such a way that passengers have to wait less on the bus stops and buses drive to the bus stops where passengers are waiting instead of driving to the Bus Stops where there are no passengers.

Fig. 3 shows the algorithm flow for The Flexible Bus Systems. Passenger after reaching the Bus Stop punches the RFID Card and all the information (Passenger ID, Destination etc) is transferred to Control Centre which then sends the info on which Bus to ride. Similarly info for all the Buses are transferred to Control Centre through Bus Stops and then Route info for the Buses are transferred to Buses through the Bus Stops. Navigation is installed in the buses which guides the Buses about the routes.

Fig. 4 shows that a Traditional Bus System has a fixed route, it drives from 1 25 and then back from 25 1. The route will remain the same even if there are no passengers on Bus Stop3 and Bus Stop4. However in The Flexible Bus System the buses can change the routes dynamically depending upon the demand of the passenger. As shown in Fig. 4 every Bus Stop is connected to the Bus Stop next to it. For example Bus Stop1 is connected to Bus Stop2 and Bus Stop10. For example if BusA is on Bus Stop2 and a passenger is waiting on Bus Stop9, then instead of going to

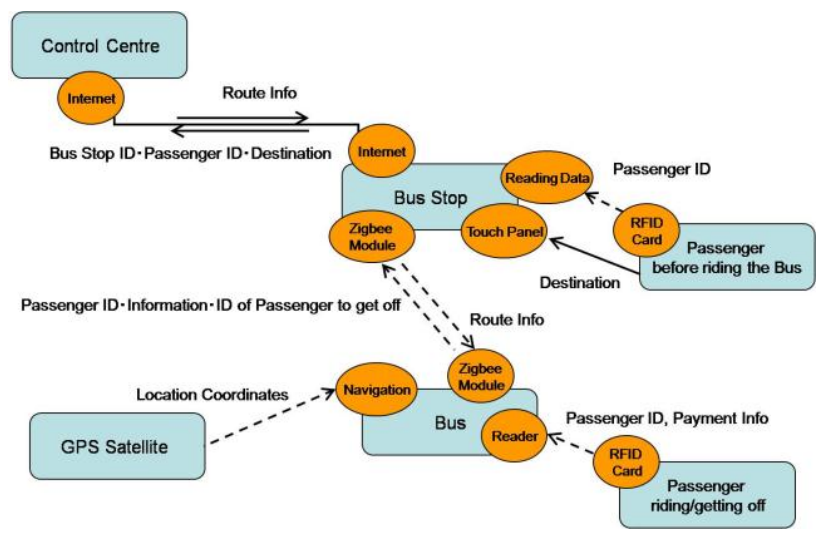

Figure 3. Algorithm flow for The Flexible Bus Systems
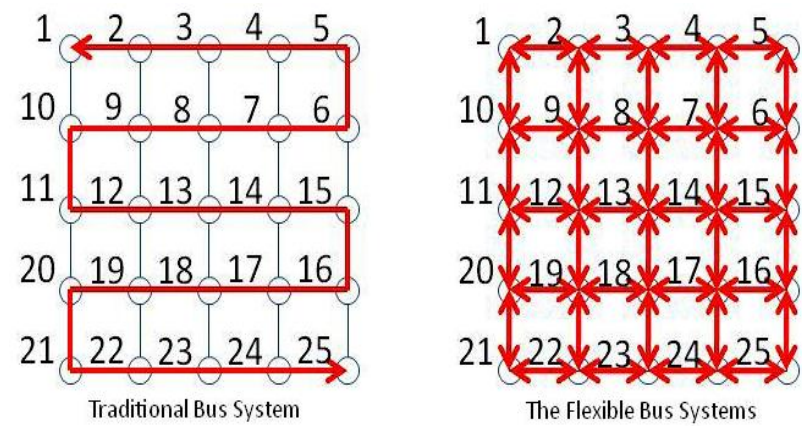

Figure 4. Traditional Bus System and the Flexible Bus System Grid Model

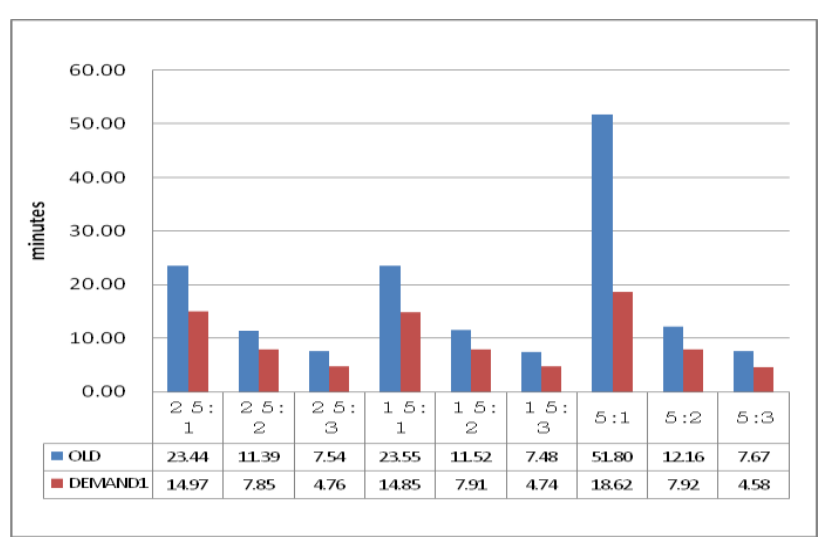

Figure 5. Average Wait Time for Passengers on Bus Stop

the Bus Stop9 by driving to all the Bus Stops from 2 9, the Bus will directly drive to Bus Stop9 to pick up the passenger. This way the wait time of the passenger waiting on Bus Stop9 will be less as compared to the case in which Bus has to drive from 2 9. The Flexible Bus System will not only decrease the wait time of the passengers but it will also decrease the drive time of the Buses which will greatly reduce the total cost of the System.

A smart algorithm is required to efficiently perform the tasks discussed in Fig. 4. We are working on an algorithm that can perform these jobs by keeping the wait time of the passengers on the Bus Stops and Ride time of the passengers on the Bus at a low side. Different simulations are been carried out for this purpose using our Simulator called "Konno Simulator".

Fig.5 shows the comparison of Wait time of passengers on the Bus Stop in Traditional Bus Systems and The Flexible Bus Systems. 
In Fig. 5 OLD is "Traditional Bus Systems" and DEMAND1 is "The Flexible Bus Systems". Ratios (25:1, 15:2, 5:3 etc) shown in Fig.5 are No. of Passenger: No. of Buses. Our simulation results show that using our algorithm total wait time of the passengers waiting on the Bus Stops can be reduced.

In Fig. 6 OLD is "Traditional Bus Systems" and DEMAND1 is "The Flexible Bus Systems". Our simulation results show that using our algorithm ride time of the passengers on the buses is also less than that of ride time of the passengers on the buses in Traditional Bus Systems as shown in Fig.6.

\section{Why USE ZIGBEE?}

Zigbee is low power and low cost which will help this system to be deployed in remote areas as well, where power and cost are major concern.

A. Zigbee vs. Long Range Wireless Technologies(3G, WiMax)

- Long range wireless technologies like $3 \mathrm{G}$ or WiMax are very expensive as compared to Zigbee, they are expensive to install and expensive to maintain.

- Long range wireless technologies are very much power consuming which make them difficult to install in remote areas.

- Licensing can be an issue for long range wireless technologies in some parts of the world.

- Long range wireless technologies are not available in all parts of the world, for example 3G networks are still not available in South Asia. Similarly even in the developed countries like Japan and America there are still large rural areas where long range wireless technologies are unavailable.

B. Zigbee vs. Short Range Wireless Technologies(Wi-Fi)

- Range for most of the Short range wireless technologies is very short (only few meters).

- The range for short range wireless technologies can be increased by adding relays but that will increase the total cost of the system.

- Short range wireless technologies are more power consuming than Zigbee which makes them difficult to install in remote areas.

- Noise can be an issue if other Wi-Fi networks are available in the surroundings.

The above mentioned reasons are the main reasons why Zigbee is preferred in the Flexible Bus Systems instead of other short range wireless technologies and long range wireless technologies.

\section{ZigBeE COMMUNICATION}

Zigbee Communication between Bus and Bus Stops are the major concern of this paper. The reason Zigbee is given priority over the other short range wireless technologies like $\mathrm{WiFi}$ is that in this research only few bytes of data is to be transferred using short range wireless technologies, no heavy data like Audio or Video is transferred so Zigbee seems to be a good alternative to Wi-Fi. With heavy data comes more power consumption which can be a concern in rural areas where power is not easily available. As described earlier Buses and Bus Stops are going to communicate with each other through Zigbee. Since Control

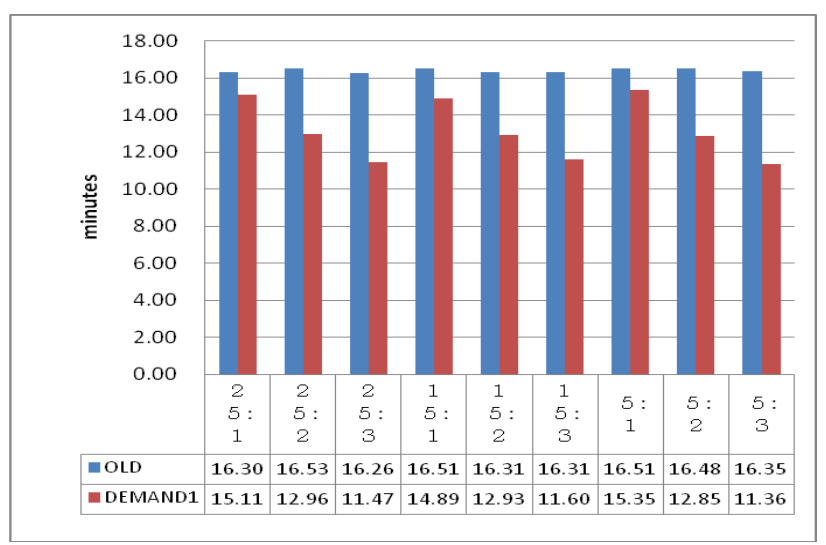

Figure 6. Average Ride Time for Passengers on Bus

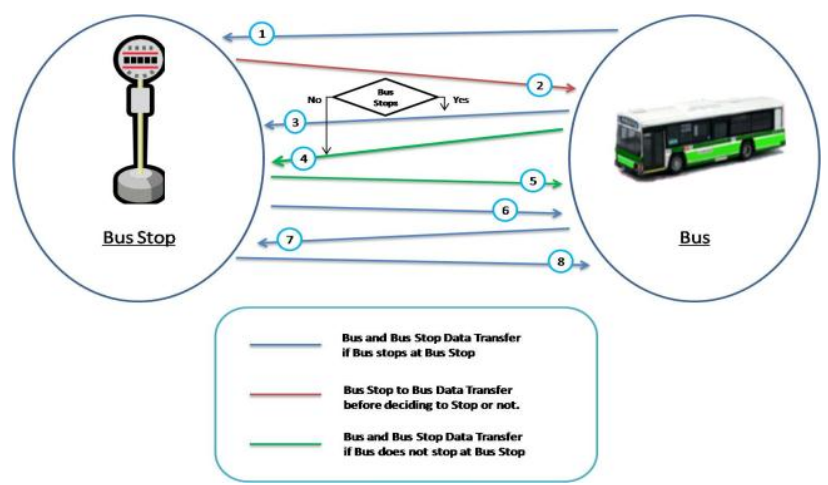

Figure 7. Data Transfer Sequence between Buses and Bus Stops

Centre is aware of all the ongoing and carrying all the information about all the buses and bus stops, the information is first transferred to corresponding bus stop about the upcoming bus. Bus Stops and Control Centre are always connected to each other through the internet (Wired or Wireless) so information between Bus Stops and Control Centre can be easily shared.

Major concern is the transfer of information between the Bus Stops and Buses and that is to be done through Zigbee. This is the core of this research and so the information transfer between the Buses and the Bus Stops are carefully thought of. Fig. 6 shows the sequence of information transfer between Buses and the Bus Stops through Zigbee.

As soon as Bus enters the communication range of the Bus Stop, information exchange starts. The numbers 1 8 in Fig. 7 are described below.

1. Bus sends the Bus ID to Bus Stop.

2. Bus Stop authenticates the request and requests the Bus to Stop or Don't Stop at current Bus Stop.

3. If Bus is requested to stop at current Bus Stop, Bus sends the stopping signal to Bus Stop.

4. If Bus is requested to pass the Bus Stop without stopping, it sends the Non-Stop passing signal to Bus Stop and requests Next Bus Stop ID.

5. Bus Stop sends the Next Bus Stop ID to the Bus.

6. In case of Bus stopped at current Bus Stop, after the Passengers rode the Bus, Bus Stop requests for the No. of Passengers in the Bus.

7. Bus sends the No. of passengers in the Bus to the Bus Stop and requests for Next Bus Stop ID.

8. Bus Stop sends the Next Bus Stop ID to the Bus. 
The decision of stopping at Bus Stop is made by Control Centre and is to be made on following conditions

- No. of passengers to get off on this Bus Stop

- No. of passengers to ride on this Bus

- Seats available in this Bus

- Destination of the passengers

Each time information/request is sent by the Bus to the Bus Stop, the information is sent to the Control Centre by the Bus Stop. The Control Centre checks for the validity of the data and sends it back to the Bus Stop from where the data is sent to the Bus. Fig. 8 is a flow chart depiction of Fig. 7 showing an easy to understand flow of information transfer between the Bus and the Bus stop.

All the information received from Bus (No. of passengers in the Bus) which is now carried by the Bus Stop will be transferred to the Control Centre through the internet after the Bus leaves the Bus Stop.

\section{CONDUCTED EXPERIMENTS}

Different experiments are performed to check whether Zigbee is suited for this kind of System (Intelligent Bus Systems) or not. Below are the details of experiments. All the experiments are conducted using Max Stream Xbee Pro.

Below are the conditions in which experiments are conducted.

- Maximum distance between Xbee Bus and Xbee Bus stop is $100 \mathrm{~m}$ with maximum height of $2 \mathrm{~m}$.

- Maximum No. of Bytes sent is 7 Bytes.

- Experiments are conducted using the Data Transfer Sequence shown in Fig. 6 and Fig. 7.

- Fig.9. describes the targets for the experiments. As shown in Fig.9 the communication range of Zigbee Modules (Bus and the Bus Stop) is $100 \mathrm{~m}$, so whenever the Bus enters this range from the Bus Stop, it will start communicating with the Bus Stop. The communication between the Bus and the Bus Stop should complete (finish) before a safe distance so that Bus can easily stop at the upcoming Bus Stop if the passenger is available or can easily take an alternative route if no passenger is available on the upcoming Bus Stop. We consider this Safe distance to be $50 \mathrm{~m}$ as shown in Fig.9.

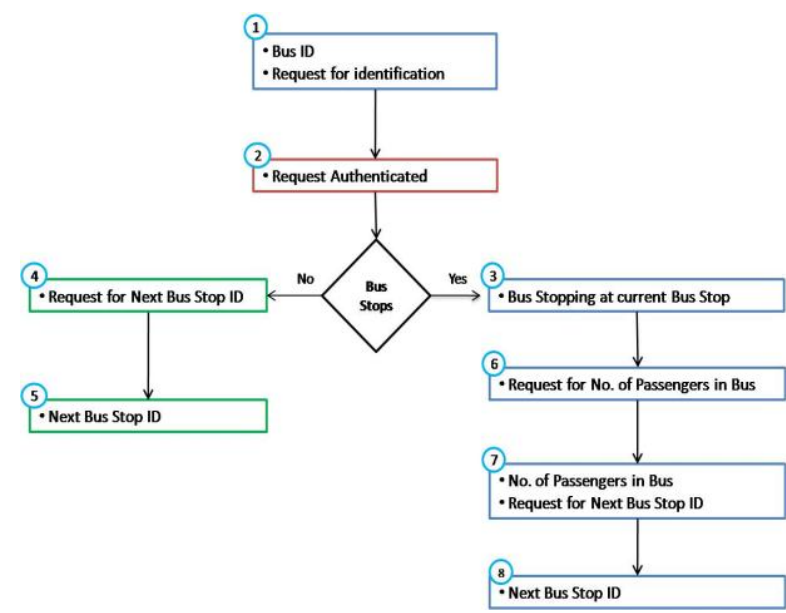

Figure 8. Data Transfer Flow Chart between Buses and Bus Stops

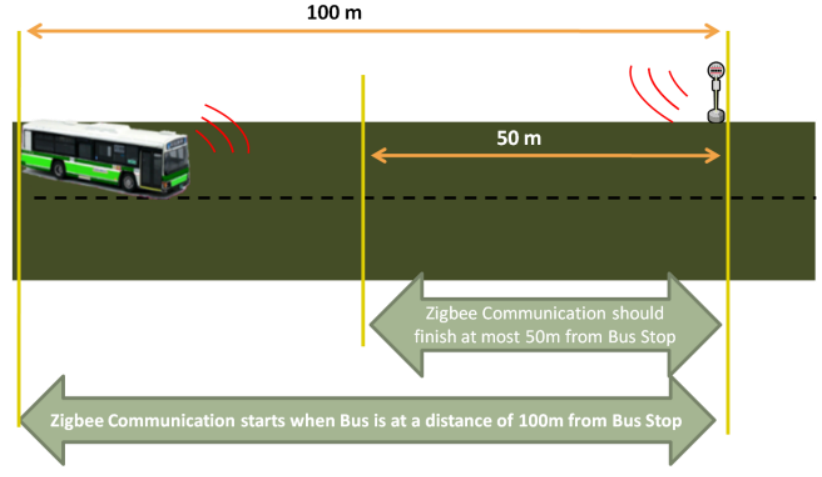

Figure 9. Targets for the experiments

Three types of experiments are conducted to check the eligibility of Zigbee for The Flexible Bus Systems.

1) Zigbee Communication on straight road with clear Line of Sight.

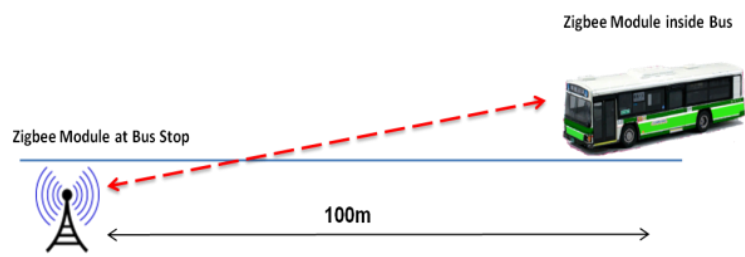

Figure 10. Zigbee Communicate with Clear Line of Sight

2) Zigbee Communication on curve with No Line of Sight (Trees as Hurdles)

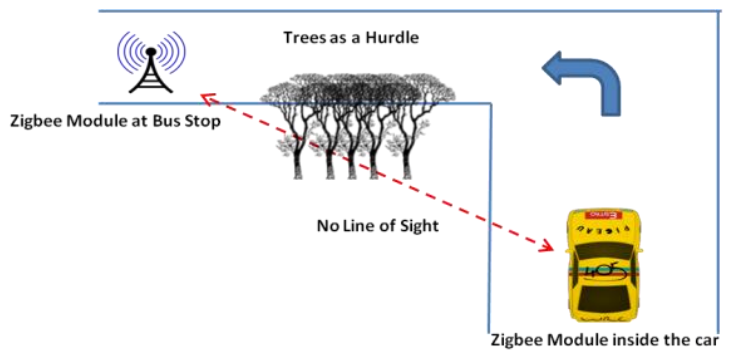

Figure 11. Zigbee Communicate with No Line of Sight (trees as hurdle)

3) Zigbee Communication on curve with No Line of Sight (Buildings as Hurdles)

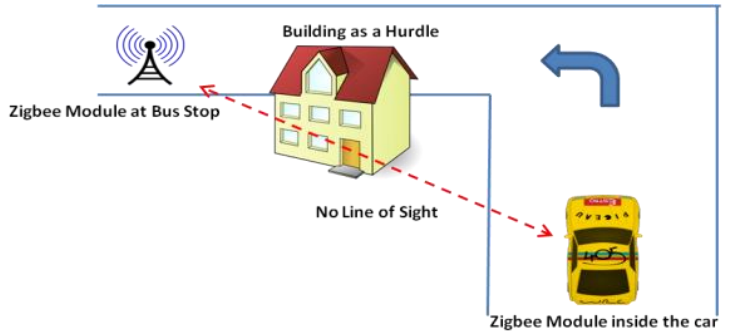

Figure 12. Zigbee Communicate with No Clear Line of Sight (Buildings as hurdle)

Table I shows the data collected for Experiment 1 when there is clear line of sight and the road is straight. 
TABLE I.

ZIGBEE COMMUNICATION ON STRAIGHT ROAD (LOS)

\begin{tabular}{|l|l|l|l|l|}
\hline $\begin{array}{c}\text { Distance } \\
(\mathbf{m})\end{array}$ & $\begin{array}{c}\text { No. of } \\
\text { Times Sent }\end{array}$ & $\begin{array}{c}\text { No. of Times } \\
\text { received }\end{array}$ & $\begin{array}{c}\text { Sent } \\
\text { every }\end{array}$ & $\begin{array}{c}\text { Error Per- } \\
\text { centage }\end{array}$ \\
\hline $100 \mathrm{~m}$ & 6 & 6 & $1 \mathrm{sec}$ & $0.00 \%$ \\
\hline $100 \mathrm{~m}$ & 6 & 6 & $1 \mathrm{sec}$ & $0.00 \%$ \\
\hline $100 \mathrm{~m}$ & 6 & 6 & $1 \mathrm{sec}$ & $0.00 \%$ \\
\hline
\end{tabular}

As shown in Table I, there are no errors when Zigbee Data transfer is checked on the straight road with clear line of sight which shows that Zigbee can be used on straight roads with clear line of sight without any doubts.

Table II shows the data collected for Experiment 2 when there is no clear line of sight and there is a curve/turn on road which has some rough trees around.

TABLE II.

ZIGBEE COMMUNICATION ON STRAIGHT ROAD (NO LOS WITH TREES)

\begin{tabular}{|l|l|l|l|l|}
\hline $\begin{array}{c}\text { Distance } \\
(\mathbf{m})\end{array}$ & $\begin{array}{c}\text { No. of } \\
\text { Times Sent }\end{array}$ & $\begin{array}{c}\text { No. of Times } \\
\text { received }\end{array}$ & $\begin{array}{c}\text { Sent } \\
\text { every }\end{array}$ & $\begin{array}{c}\text { Error Per- } \\
\text { centage }\end{array}$ \\
\hline $100 \mathrm{~m}$ & 6 & 6 & $1 \mathrm{sec}$ & $0.00 \%$ \\
\hline $100 \mathrm{~m}$ & 6 & 5 & $1 \mathrm{sec}$ & $16.67 \%$ \\
\hline $100 \mathrm{~m}$ & 6 & 5 & $1 \mathrm{sec}$ & $16.67 \%$ \\
\hline $100 \mathrm{~m}$ & 6 & 3 & $1 \mathrm{sec}$ & $50.00 \%$ \\
\hline $100 \mathrm{~m}$ & 6 & 5 & $1 \mathrm{sec}$ & $16.67 \%$ \\
\hline $100 \mathrm{~m}$ & 6 & 4 & $1 \mathrm{sec}$ & $33.33 \%$ \\
\hline Average & $\mathbf{6}$ & $\mathbf{4 . 6 7}$ & $\mathbf{1 ~ s e c}$ & $\mathbf{2 2 . 2 2 \%}$ \\
\hline
\end{tabular}

Table II shows the data which is still quite encouraging although there are a few errors, but the average shows that every 6 times data is sent 4.67 times it is received. As described earlier if the data is received even only once the communication can be done easily and bus can get to know if it has to stop on the upcoming Bus Stop or not but as data is received more than 1 times, in this case 4.67 times which is far more times it should be received, so there shouldn't be any problem in data communication.

Table III shows the data collected for Experiment 3 when there is no clear line of sight and there is a curve/turn on road which has some buildings around.

TABLE III.

ZIGBEE COMMUNICATION ON STRAIGHT ROAD (NO LOS WITH BUILDINGS)

\begin{tabular}{|l|l|l|l|l|}
\hline $\begin{array}{c}\text { Distance } \\
(\mathbf{m})\end{array}$ & $\begin{array}{c}\text { No. of } \\
\text { Times Sent }\end{array}$ & $\begin{array}{c}\text { No. of Times } \\
\text { received }\end{array}$ & $\begin{array}{c}\text { Sent } \\
\text { every }\end{array}$ & $\begin{array}{c}\text { Error Per- } \\
\text { centage }\end{array}$ \\
\hline $100 \mathrm{~m}$ & 6 & 3 & $1 \mathrm{sec}$ & $50.00 \%$ \\
\hline $100 \mathrm{~m}$ & 6 & 2 & $1 \mathrm{sec}$ & $66.67 \%$ \\
\hline $100 \mathrm{~m}$ & 6 & 1 & $1 \mathrm{sec}$ & $83.33 \%$ \\
\hline Average & $\mathbf{6}$ & $\mathbf{2}$ & $\mathbf{1 ~ s e c}$ & $\mathbf{6 6 . 6 7 \%}$ \\
\hline $80 \mathrm{~m}$ & 6 & 4 & $1 \mathrm{sec}$ & $33.33 \%$ \\
\hline $80 \mathrm{~m}$ & 6 & 2 & $1 \mathrm{sec}$ & $66.67 \%$ \\
\hline $80 \mathrm{~m}$ & 6 & 3 & $1 \mathrm{sec}$ & $50.00 \%$ \\
\hline $80 \mathrm{~m}$ & 6 & 5 & $1 \mathrm{sec}$ & $16.67 \%$ \\
\hline $80 \mathrm{~m}$ & 6 & 4 & $1 \mathrm{sec}$ & $33.33 \%$ \\
\hline Average & $\mathbf{6}$ & $\mathbf{3 . 6}$ & $\mathbf{1 ~ s e c}$ & $\mathbf{4 0 . 0 0 \%}$ \\
\hline $50 \mathrm{~m}$ & 6 & 4 & $1 \mathrm{sec}$ & $33.33 \%$ \\
\hline $50 \mathrm{~m}$ & 6 & 5 & $1 \mathrm{sec}$ & $16.67 \%$ \\
\hline $50 \mathrm{~m}$ & 6 & 6 & $1 \mathrm{sec}$ & $0.00 \%$ \\
\hline $50 \mathrm{~m}$ & 6 & 3 & $1 \mathrm{sec}$ & $50.00 \%$ \\
\hline $50 \mathrm{~m}$ & 6 & 6 & $1 \mathrm{sec}$ & $0.00 \%$ \\
\hline Average & $\mathbf{6}$ & $\mathbf{4 . 8}$ & $\mathbf{1 ~ s e c}$ & $\mathbf{2 0 . 0 0 \%}$ \\
\hline
\end{tabular}

The data shown in Table III is not very encouraging as error percentage is at high side. Table shows that at distance of $100 \mathrm{~m}$ error rate is $66.67 \%$ which means that data is received only 2 times out of 6 which is at a risky side.
Similarly at a distance of $80 \mathrm{~m}$ on average data is received 3.6 times out of 6 which is better than that at $100 \mathrm{~m}$ but still below par. At a distance of $50 \mathrm{~m}$ the data is encouraging getting received 4.8 times out of 6 . If we concentrate on data for $50 \mathrm{~m}$, it seems as if data communication can be done easily as data is received quite frequently but the problem with $50 \mathrm{~m}$ is that if Bus is sent a signal by the Bus Stop to stop at this Bus Stop when Bus is just 50m away from the Bus Stop, it will be difficult for the bus to stop with a speed of $60 \mathrm{~km} / \mathrm{h}$ which is the maximum speed limit here in Japan.

\section{EXPERIMENTS OUTCOME}

The conducted experiments showed the following results:

- Different experiments showed that the main factor affecting Zigbee communication is the distance between the Zigbee modules (Xbee Bus and Xbee Bus Stop in this case). The more the distance the less efficient is the Zigbee communication.

- The bigger and denser the hurdles, more difficult it is to communicate between the Zigbee Modules.

- The straighter the roads, the better it is to communicate between Zigbee Modules.

- If Bus Stops are close to each other (within 100m) Zigbee modules can cause interference.

- A suitable height of about $2 \mathrm{~m}$ can increase the efficiency of Zigbee Data Transfer.

- Speed of the Bus has no significant effect on Zigbee Data Transfer.

- Weather has no significant effect on Zigbee Data Transfer.

- Signals of other wireless technologies like Wi-Fi, 3G and Bluetooth have no distraction for Zigbee signals.

\section{PROBLEMS AND PROPOSED SOLUTIONS}

The outcome of the experiments shows some problems which can affect the Flexible Bus System. Below are the problems and their proposed solutions:-

\section{A. Problems}

1. Strong hurdles like trees and buildings affect Zigbee communication.

2. Zigbee modules on other Bus Stops can interfere with each other.

\section{B. Proposed Solutions}

1. The problem of Strong Hurdles affecting Zigbee communication can be solved by

a) Using Zigbee Relays to increase the line of sight of the Zigbee modules.

b) Building the Bus Stops at the places where there are less hurdles and less noise.

2. The problem of Zigbee modules interfering with each other can be solved by

a) Using Unidirectional Antenna for Zigbee Modules.

b) Using the software approach and making Bus Stop communicate only with the Buses which Control Centre asks it to communicate to. 
PAPER

The FleXible Bus Systems Using ZigBeE as a Communication Medium

\section{SUMMARY}

The Flexible Bus Systems is an efficient and a smart Demand Responsive Transit (DRT). It is flexible in a sense that it can change dynamically according to the demands of the passengers. The system can fulfil the demands of the passengers in a way that they have to wait less on the Bus Stops and even if they miss the Bus they can be entertained by the next bus without waiting for very long. The use of Zigbee for communication between the Buses and the Bus Stops greatly reduce the total cost of the system. Everything is connected to the Control Centre which is the brain of the system. Control Centre and Bus Stops are connected through the internet and Buses and Control Centre are connected to each other through Bus Stops. All the characters (Buses, Bus Stops and Passengers) are updated with latest information all the times which makes The Flexible Bus Systems more information rich and reliable.

\section{ACKNOWLEDGMENT}

This work is supported by the Strategic Information and Communication R\&D Promotion Programme 102302005 from the Japanese Ministry of Internal Affairs and Communications.

\section{REFERENCES}

[1] Shahin Farahani, Zigbee Wireless Networks and Transceivers

[2] Lee, E., Ryu, K., Paik, I.: A Concept for Ubiquitous Transportation Systems and Related Development Methodology. In: International IEEE Conference on Intelligent Transportation Systems, pp.37-42 (2008). doi:10.1109/ITSC.2008.4732709

[3] Yuwei Li, Jessica Wang, Justin Chen, Michael Cassidy, Design of a Demand-Responsive Transit System (California PATH Working Paper UCB-ITS-PWP-2007-4)
[4] ZHANG Feizhou, CAO Xuejun, YANG Dongkai, Intelligent Scheduling of Public Traffic Vehicles Based on a Hybrid Genetic Algorithm (TSINGHUA SCIENCE AND TECHNOLOGY, ISSN 1007-0214 09/25 pp625-631, Volume 13, Number 5, October 2008)

[5] Jin $\mathrm{Xu}$, Zhe Huang, An Intelligent Model for Urban Demandresponsive Transport System Control (Journal of Software, Vol. 4, No. 7, September 2009)

[6] R'emy Chevrier, Philippe Canalda, Pascal Chatonnay and Didier Josselin, Comparison of three Algorithms for solving the Convergent Demand Responsive Transportation Problem (Proceedings of the IEEE ITSC 2006)

[7] Zigbee Standards Organization, Zigbee Specification, ZigBee Document 053474r17, January 17, 2008.

[8] Tomohiro Utsumi, Shin Konno, Yusuke Kanno, Ken-ichi Yukimatsu, Mahito Kobayashi, Masashi Hashimoto, A Feasibility study on the Buffer-Less Routing Networks using Deflection Routing Control (Proceedings of IEICE Vol. J92-B No. 11 pp. 17411749 2009).

[9] Razi Iqbal, Kenichi Yukimatsu and Tatsuya Ichikawa, "A Research on the Flexible Bus Systems Using Zigbee as a Communication Medium", in proceedings of 4th IFIP International Conference on New Technologies, Mobility and Security, in Paris, France, 7-10 February, 2010.

\section{AUTHORS}

Razi Iqbal, Kenichi Yukimatsu, and Tatsuya Ichikawa are with the Department of Computer Science and Engineering, Graduate School of Engineering and Resource Science, Akita University, 1-1 Tegata-gakuen-machi, Akita, Akita 010-8502, JAPAN.

Received March $2^{\text {nd }}, 2011$. Published as resubmitted by the authors June $11^{\text {th }}, 2011$. 